\title{
Short communication: Changes in body temperature of calves up to 2 months of age as affected by time of day, age, and ambient temperature
}

\author{
T. M. Hill, ${ }^{1}$ H. G. Bateman II, ${ }^{2}$ F. X. Suarez-Mena, T. S. Dennis, and R. L. Schlotterbeck \\ Nurture Research Center, Provimi, Brookville, OH 45309
}

\begin{abstract}
Extensive measurements of calf body temperature are limited in the literature. In this study, body temperatures were collected by taping a data logger to the skin over the tail vein opposing the rectum of Holstein calves between 4 and $60 \mathrm{~d}$ of age during 3 different periods of the summer and fall. The summer period was separated into moderate $\left(21-33^{\circ} \mathrm{C}\right.$ average low to high) and hot $\left(25-37^{\circ} \mathrm{C}\right)$ periods, whereas the fall exhibited cool $\left(11-19^{\circ} \mathrm{C}\right)$ ambient temperatures. Tail temperatures were compared in a mixed model ANOVA using ambient temperature, age of calf, and time of day (10-min increments) as fixed effects and calf as a random effect. Measures within calf were modeled as repeated effects of type autoregressive 1. Calf temperature increased $0.0325^{\circ} \mathrm{C}( \pm 0.00035)$ per $1^{\circ} \mathrm{C}$ increase in ambient temperature. Body temperature varied in a distinct, diurnal pattern with time of day, with body temperatures being lowest around $0800 \mathrm{~h}$ and highest between 1700 and 2200 h. During periods of hot weather, the highest calf temperature was later in the day $(\sim 2200 \mathrm{~h})$. Calf minimum, maximum, and average body temperatures were all higher in hot than in moderate periods and higher in moderate than in cool periods.
\end{abstract}

Key words: calves, body temperature, environment

\section{Short Communication}

Body temperature regulation in neonatal calves is metabolically immature (NRC, 2001). Additionally, calf performance is greatly affected by ambient temperature (Bateman et al., 2012), and extremes in ambient temperatures can negatively affect calf immunity (Carroll et al., 2012). Mature, healthy cattle maintain thermoneutrality through adjustments in behavior, heat production, heat transfer to and loss from their surface,

Received February 5, 2016.

Accepted July 17, 2016.

${ }^{1}$ Corresponding author: mhill@provimi-na.com

${ }^{2}$ Deceased. and evaporation (Macauly et al., 1995). Metabolic and physiological changes and environmental stresses can change body temperature (Carroll et al., 2012). Body temperatures are also important for farm personnel and veterinarians to assess calf health.

Extensive measurements of calf body temperature are limited. Tympanic temperatures were extensively measured in young dairy calves and found to have a diurnal change over the 24-h day similar to adult dairy cows (Macauly et al., 1995). Whereas the rectum is the standard place to measure temperature, rectal temperatures are subject to errors, and if manually taken are laborious and disruptive to animal behavior (Burfeind et al., 2010). Errors with taking rectal temperatures include the procedure, the device, the depth of insertion into the rectum, and defecation, and errors can amount to as much as $\pm 0.5^{\circ} \mathrm{C}$ (Burfeind et al., 2010). A procedure for an indwelling rectal data logger allows temperatures to be recorded for a few days, as well as reduce labor and disruption of animal behavior (Reuter et al., 2010). A procedure for using a small data logger taped to the skin near the tail vein of the calf opposing the rectum has been reported to successfully measure body temperature, as tail temperature correlated $\left(R^{2}=0.80\right)$ with rectal temperature (Nogami et al., 2013), and appears most useful for long-term, extensive measurements of body temperature (Esselburn et al., 2013; Nogami et al., 2013). Data loggers used by Esselburn et al. (2013) were attached directly to a calf's tail skin over the tail vein, and Dikmen et al. (2014) used vaginal indwelling loggers, both of which are precise to $\pm 0.0625^{\circ} \mathrm{C}$ (Maxim Integrated Products Inc., Sunnyvale, CA). Therefore, the objective of the current research was to extensively measure the body temperature of calves between 4 and $60 \mathrm{~d}$ of age as affected by time of day, age, and ambient temperature.

Calves were cared for by acceptable practices as described in the Guide for the Care and Use of Agricultural Animals in Research and Teaching (FASS, 2010) and housed and managed under conventional farm procedures in the summer and fall. Four groups of 12 to 20 male Holstein calves ( 56 total), initially 2 to $4 \mathrm{~d}$ of age, from a single dairy farm were transported $3.5 \mathrm{~h}$ to 
the Nurture Research Center in southwest Ohio during summer and fall seasons. The first 3 groups of 12 calves each were received $35 \mathrm{~d}$ apart. The fourth group (20 calves) was received $70 \mathrm{~d}$ after the third group. Calves were housed in $1.2 \times 2.4 \mathrm{~m}$ individual pens with a coarse rock, tile-drained floor bedded with straw in a curtain-sided, naturally ventilated barn with no added heat. Management practices including vaccinations and medical treatments during the trial were based on the recommendations of a veterinarian. Upon arrival, calves were fed $0.66 \mathrm{~kg}$ of DM daily from a $27 \% \mathrm{CP}, 17 \%$ fat (DM basis) mixed ration for $39 \mathrm{~d}$ that was divided into 2 equal meals at 0630 and $1600 \mathrm{~h}$. The mixed ration was fed at $0.33 \mathrm{~kg}$ of DM daily at $0630 \mathrm{~h}$ from 40 to 42 $\mathrm{d}$ to facilitate weaning. Starter (20\% CP on DM basis) and water were fed ad libitum throughout.

Data loggers (Thermocron model DS1922L-F5\#, Maxim Integrated Products Inc.; precise to $\pm 0.0625^{\circ} \mathrm{C}$ ) were taped to the skin over the tail vein opposing the rectum using flexible tape (Vetrap, 3M, St. Paul, MN). Temperatures were captured every $10 \mathrm{~min}$ and stored on the data logger beginning at $4 \mathrm{~d}$ of age to up to 60 $\mathrm{d}$ of age. Data loggers were on each calf for $>53 \mathrm{~d} /$ calf. All data loggers were removed twice through the trial for $<24 \mathrm{~h}$ total to download the data to a personal computer (and import it into a spreadsheet) and replace the tape. Data loggers were also removed and replaced on the tail if tape appeared to be loose. A macro was written to remove any measurements less than $37.8^{\circ} \mathrm{C}$, and then any measurement more or less than $0.25^{\circ} \mathrm{C}$ from the previous measurement was removed in an attempt to eliminate any erroneous values. The temperature thresholds of $37.8^{\circ} \mathrm{C}$ and the $0.25^{\circ} \mathrm{C}$ change were based on findings from casual observations of behavior, noted times of the behavior in specific calves, and temperature recordings at noted times during the first 4 $\mathrm{d}$ in the first set of calves. Behaviors that lead to erroneous values were extreme tail movements in excited calves consuming milk, calves sleeping on their sides where the tail was somewhat separated from the body, loose tape that secured the data loggers to the tail, and excited calves playing with their tails raised during pen maintenance and bedding by technicians. These behaviors frequently resulted in temperatures $<37.8^{\circ} \mathrm{C}$. Removed measurements ranged from $<2 \%$ of total per calf to $<7 \%$ of total per calf. Additionally, a data logger was taped to a room temperature sensor and recording device (TP125 temperature and humidity recorder, Dickson, Addison, IL) suspended on a wire $1.5 \mathrm{~m}$ above the floor of the nursery to record ambient temperature.

Statistical analyses of the data were conducted using Proc MIXED in SAS (version 8, SAS Institute Inc., Cary, NC). Rectal and tail temperatures were compared in a mixed model regression using time of day, day, and calf as random effects. Measures within calf were modeled as repeated effects. Day and time of day were not significant $(P>0.1)$ and removed from the model. To evaluate what affected calf temperatures, tail temperatures were compared in a mixed model ANOVA using ambient temperature, age of calf, and time of the day (10-min increments) as fixed effects and calf as a random effect. Measures within calf were modeled as repeated effects. Groups of days where ambient temperatures were distinctly different (hot, moderate, and cool) were compared in a completely randomized design with repeated measures of day using the mixed model ANOVA where minimum, maximum, and average temperatures of each day were used in the ANOVA. Means were separated with a protected LSD test. An auto-regressive type 1 covariance matrix was employed in each analyses as determined using Akaike's information criteria.

The functionality of the data loggers were evaluated and compared with other temperature measuring devices in various ways. One hundred readings from the data logger that was taped to the room temperature sensor and the room temperature sensor were randomly selected during the first $4 \mathrm{~d}$ of the first group of calves to compare ambient temperature readings. Readings were rounded to 1 decimal place, compared, and no paired readings were different. When data loggers were first removed from the calves, they were immediately tested in a hot water bath with a temperature taken using a rectal temperature probe to 1 decimal place (M700 digital thermometer, GLA Agricultural Electronics, San Luis Obispo, CA). A hot water bath was constructed using a large flat-bottomed Pyrex (World Kitchen LLC, Rosemont, IL) pie plate on a hot plate set to a low temperature (approximately $38.5^{\circ} \mathrm{C}$ ) and subsequently a higher temperature (approximately $39.3^{\circ} \mathrm{C}$ ). Each data logger was placed in smaller Pyrex pie plate set on $0.5-\mathrm{cm}$ steel spacers within the hot water bath. After $30 \mathrm{~min}$ at each temperature, the data loggers were removed. The water bath temperature was checked before and after data logger immersion with the rectal temperature probe. Two readings from each data logger and the 2 readings from the rectal probe were compared at each water bath temperature after rounding to 1 decimal place. No paired readings differed. Comparisons of the rectal temperature probe, room temperature sensor, and data loggers agreed suggesting the data loggers were functioning properly.

Calf tail temperatures from the data loggers were compared with a paired rectal temperature taken with the rectal temperature probe. Rectal temperatures were taken on 25 different days, 3 times daily at approximately 0600, 1100, and $1700 \mathrm{~h}$, with the exact time and calf recorded in the first group of 12 calves (900 paired 
temperatures). The relationship was rectal temperature $\left({ }^{\circ} \mathrm{C}\right)=19.92( \pm 0.987 ; P<0.0001)+0.496( \pm 0.0255$; $P<0.0001)$ tail temperature $\left({ }^{\circ} \mathrm{C} ; \mathrm{R}^{2}=0.61\right)$. The difference between rectal temperature and data logger measurements was similar to the variation reported with measuring rectal temperature by hand that was influenced by procedure, thermometer type, defecation, and the depth of penetration into the rectum (Burfeind et al., 2010). Tail temperatures might be expected to be lower than rectal temperatures, as they are external and could have been influenced by activities that separated the tail from the body (i.e., tail-wagging, defecation, and so on; Nogami et al., 2013).

Tail temperature was influenced by ambient temperature (Figure 1). The singular relationship of tail temperature and ambient temperature was significant, where tail temperature $\left({ }^{\circ} \mathrm{C}\right)=38.0( \pm 0.0075)+0.0325$ $( \pm 0.00035)$ ambient temperature $\left({ }^{\circ} \mathrm{C} ; P<0.0001 ; \mathrm{R}^{2}=\right.$ 0.52 ). Over the course of $24 \mathrm{~h}$, tail temperature changed diurnally with the lowest temperature at approximately $0800 \mathrm{~h}$ and the highest temperature at 1700 to $2200 \mathrm{~h}$ depending upon ambient temperature (Figure 2).

Inspection of the data collected revealed 3 distinctly different ambient temperature periods that resulted in different time of day of the maximum tail temperatures and different maximum tail temperatures. The summer measurements included a period of $6 \mathrm{~d}$ (12 calves) when the ambient temperature was much higher than the rest of the data. This 6-d period was labeled hot (daily maximum ambient temperatures exceeded $35.5^{\circ} \mathrm{C}$ and ranged from $25^{\circ} \mathrm{C}$ average low to $37^{\circ} \mathrm{C}$ average high), whereas the remaining data from the same 12 calves and the next 2 groups of 12 calves each were labeled moderate $\left(21^{\circ} \mathrm{C}\right.$ average low to $33^{\circ} \mathrm{C}$ average high, with no high temperatures greater than $35^{\circ} \mathrm{C}$ ). The data collected from the last group of calves (20 calves) was labeled cool $\left(11^{\circ} \mathrm{C}\right.$ average low to $19^{\circ} \mathrm{C}$ average high, and no high temperatures greater than $20.5^{\circ} \mathrm{C}$ ). Minimum, maximum, and average tail temperatures for each calf for each day and the time of minimum and maximum temperature for each calf each day were compared among the 3 periods of hot, moderate, and cool ambient temperatures. Minimum (38.5, 38.3 , and $38.1 \pm 0.09^{\circ} \mathrm{C}$ for hot, moderate, and cool, respectively), maximum $\left(39.8,39.3\right.$, and $38.4 \pm 0.19^{\circ} \mathrm{C}$ for hot, moderate, and cool, respectively), and average (39.1, 38.8, and $38.2 \pm 0.12^{\circ} \mathrm{C}$ for hot, moderate, and cool, respectively) temperatures all differed $(P<0.01)$ among the 3 ambient temperature periods (Figure 2). Time of minimum temperature $(0808 \pm 51 \mathrm{~h})$ did not differ among periods. Time of maximum temperature was later $(2204 \mathrm{~h}$ vs. 1712 and $1801 \pm 49 \mathrm{~h})$ in the day for calves in the hot versus cool and moderate periods $(P<0.01)$.

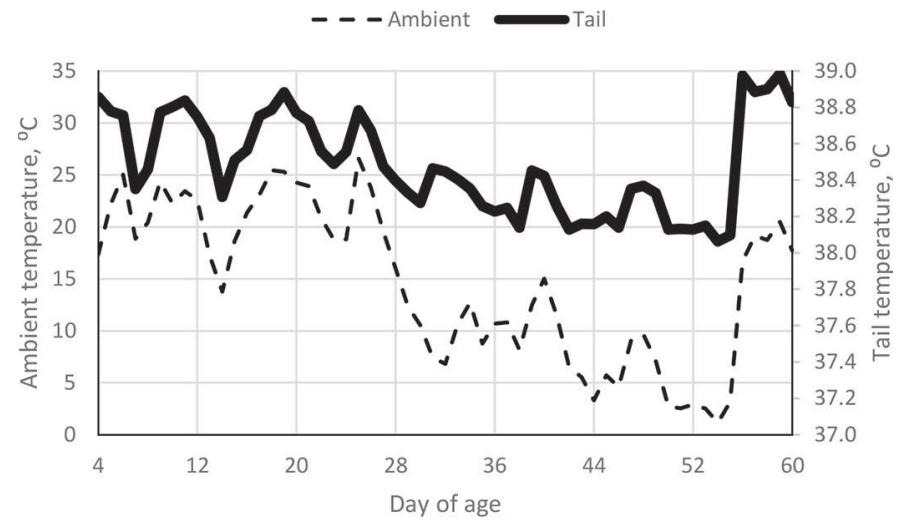

Figure 1. Change in ambient and calf tail temperature by day of age. The SEM was $1.0^{\circ} \mathrm{C}$ or less for all ambient temperatures shown, except d 5, where the SEM was $2.3^{\circ} \mathrm{C}$; SEM was $0.05^{\circ} \mathrm{C}$ or less for all tail temperatures shown, except d 5 , where the SEM was $0.12^{\circ} \mathrm{C} . \mathrm{n}=$ 56 calves.

Efforts to ameliorate the stress of extreme ambient temperatures can affect calf performance and welfare. Bedding calves in deep straw during cold weather results in greater ADG compared with calves bedded with wood shavings (Hill et al., 2007). The use of fans to cool calves during summer heat results in less panting and greater ADG of calves (Hill et al., 2011). The NRC (2001) contains energy adjustments for cold but not heat stress in calves, yet the current measurements and the meta-analysis of Bateman et al. (2012) suggest that heat stress negatively affects calf ADG.

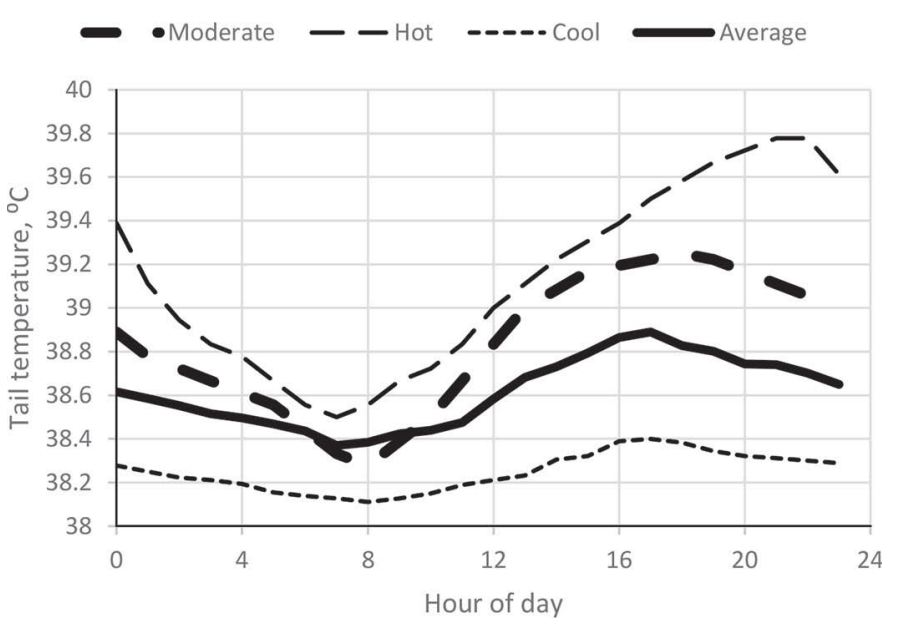

Figure 2. Change in the calf temperature over the 24-h day for the entire data set (average) and periods of moderate $\left(21^{\circ} \mathrm{C}\right.$ average low to $33^{\circ} \mathrm{C}$ average high), hot $\left(25\right.$ to $\left.37^{\circ} \mathrm{C}\right)$, and cool $\left(11\right.$ to $\left.19^{\circ} \mathrm{C}\right)$ ambient temperatures $(\mathrm{n}=56$ calves). Minimum, maximum, and average temperatures all differed $(P<0.01)$ among moderate, hot, and cool ambient temperature periods. The largest SEM was $0.043^{\circ} \mathrm{C}$ for moderate, $0.057^{\circ} \mathrm{C}$ for hot, and $0.014^{\circ} \mathrm{C}$ for cool. 
To summarize, calf temperature increased $0.0325^{\circ} \mathrm{C}$ $( \pm 0.00035)$ per $1^{\circ} \mathrm{C}$ increase in ambient temperature. Body temperature varied in a distinct, diurnal pattern with time of day, being the lowest around $0800 \mathrm{~h}$ and highest between 1700 and 2200 h. During periods of hot weather, the highest calf temperature was later in the day $(\sim 2200 \mathrm{~h})$. Calf minimum, maximum, and average body temperatures were all higher in hot than in moderate and higher in moderate than cool periods.

\section{REFERENCES}

Bateman, H. G., II, T. M. Hill, J. M. Aldrich, R. L. Schlotterbeck, and J. L. Firkins. 2012. Meta analysis of the impact of initial serum protein concentration and empirical prediction model for growth of neonatal Holstein calves through eight weeks of age. J. Dairy Sci. 95:363-369

Burfeind, O., M. A. G. von Keyserlingk, D. M. Weary, D. M. Veira, and W. Heuwieser. 2010. Short communication: Repeatability of measures of rectal temperature in dairy cows. J. Dairy Sci. 93:624-627.

Carroll, J. A., N. C. Burdicka, C. C. Chase Jr., S. W. Coleman, and D. E. Spiers. 2012. Influence of environmental temperature on the physiological, endocrine, and immune responses in livestock exposed to a provocative immune challenge. Domest. Anim. Endocrinol. 43:146-153.
Dikmen, S., F. A. Khan, H. J. Huson, T. S. Sonstegard, J. I. Moss, G. E. Dahl, and P. J. Hansen. 2014. The SLICK hair locus derived from Senepol cattle confers thermotolerance to intensively managed lactating Holstein cows. J. Dairy Sci. 97:5508-5520.

Esselburn, K. M., K. M. O’Diam, T. M. Hill, H. G. Bateman, J. M. Aldrich, R. L. Schlotterbeck, and K. M. Daniels. 2013. Intake of specific fatty acids and fat alters growth, health, and titers following vaccination in dairy calves. J. Dairy Sci. 96:5826-5835.

FASS. 2010. Guide for the Care and Use of Agricultural Animals in Agricultural Research and Teaching. 3rd ed. FASS Inc., Champaign, IL.

Hill, T. M., H. G. Bateman II, J. M. Aldrich, and R. L. Schlotterbeck. 2007. Effects of feeding rate of milk replacers and bedding material for calves in a cold naturally ventilated nursery. Prof. Anim. Sci. 23:656-664.

Hill, T. M., H. G. Bateman II, J. M. Aldrich, and R. L. Schlotterbeck. 2011. Comparisons of housing, bedding, and cooling options for dairy calves. J. Dairy Sci. 94:2138-2146.

Macauly, A. S., G. L. Hahn, D. H. Clark, and D. V. Sisson. 1995. Comparison of calf housing types and tympanic temperature rhythms in Holstein calves. J. Dairy Sci. 78:856-862.

NRC. 2001. Nutrient Requirements of Dairy Cattle. 7th rev. ed. Natl. Acad. Sci., Washington, DC.

Nogami, H., H. Okada, T. Miyamoto, R. Maeda, and T. Itoh. 2013. Wearable and compact wireless sensor nodes for measuring in temperature of the base of a calf's tail. Sens. Mater. 25:577-582.

Reuter, R. R., J. A. Carroll, L. E. Hulbert, J. W. Dailey, and M. L. Galyean. 2010. Technical note: Development of a self-contained, indwelling rectal temperature probe for cattle research. J. Anim. Sci. 88:3291-3295. 